\title{
Assessment of Health Risk Behaviours among Secondary School Students in Enugu, South-East, Nigeria
}

\author{
Omotowo Babatunde $\mathrm{I}^{1}$, Ndu Anne $\mathrm{C}^{1}$, Agwu-Umahi Olanike $\mathrm{R}^{1}$, Ezeoke Uchechukwu E ${ }^{1}$, Idoko Chinedu $\mathrm{A}^{1}$ \& \\ Umeobieri Ancilla $\mathrm{K}^{1}$ \\ ${ }^{1}$ Department of Community Medicine, College of Medicine, University of Nigeria, Enugu Campus, Nigeria \\ Correspondence: Ndu Anne C, Department of Community Medicine, College of Medicine, University of Nigeria, \\ Enugu Campus, Nigeria.
}

Received: March 1, 2017 Accepted: March 24, 2017 Online Published: April 5, 2017

doi:10.5539/gjhs.v9n7p57 URL: https://doi.org/10.5539/gjhs.v9n7p57

\begin{abstract}
Introduction: Health risk behaviours contribute to the leading causes of deaths and disability among adults and youth.
\end{abstract}

Objective: The purpose of the study was to investigate the prevalence of health risk behaviours among secondary school students in Enugu, South-East Nigeria.

Methods: This cross sectional study was conducted between May and July 2015 among 348 school students randomly selected in six secondary schools in rural and urban areas. Data was analysed using SPSS version 21, and statistical significance of association between variables was assessed using Chi-square test at $\mathrm{p}<0.05$.

Results: Overall, 348 respondents out of 360 returned the completed questionnaires. 50.6\% were females, while their mean age was $15.2 \pm 5.1$ years. Majority of respondents live with both parents $(73.9 \%)$.

Many respondents $44.5 \%$ had taken alcohol, while $13.5 \%$, and $40.8 \%$ had smoked cigarette and had sex before respectively. Also, $59.8 \%$ had experienced one form of violence, while $37.6 \%$ of them preferred fast food junks to food prepared at home.

Age, sex and class did not significantly influence participants that had taken alcohol. Also, age, sex and class did not significantly influence those that had sex in the past. However, sex significantly influenced smoking of cigarettes.

Conclusions \& Recommendations: Our results showed high percentage of health risky behaviours among secondary school students. Introduction of compulsory health education curriculum activities in schools was recommended.

Keywords: health, risky behaviours, students

\section{Introduction}

Worldwide, health risky behaviours contribute to the leading causes of death and disability among adults and youths, and also contribute to educational and social problems (Centers for Disease Control and Prevention, 2009; Schwartz, Forthun, Ravert et al., 2010). They can also cause alcohol and other drug abuse, unintentional injuries, property damage, violence including suicide, tobacco use, unhealthy dietary behaviours, physical inactivity, sexual behaviours that contribute to unintended teen pregnancy, sexually transmitted diseases, HIV, diminished lifespan, and treatment expenses (Centers for Disease Control and Prevention, 2009; Kolek, 2006).

Secondary school students are in adolescence which is typically a time when young people begin to challenge parental controls and values and to be influenced by their peers. The family is known to be an essential source of support and agent of intervention and health promotion through the school years, so relationship with parents are very important during the period (John, Mattew, Rashed, \& Will, 2012). During this period, schools become more important where the support of teachers and peers may have more influence than their home environment (John, Mattew, Rashed, \& Will, 2012; Collins \& Steinberg, 2006). Also, schools play a critical role in promoting the health and safety of young people and help them establish lifelong healthy behaviours (Centers for Disease Control and Prevention, 2009).

Health behaviour is an action taken by a person to maintain, attain, or regain good health and to prevent illness. It 
also reflects a person's health beliefs. Some common health behaviours are exercising regularly, eating a balance diet, wearing seat belts, practicing safe sex, seeking information about health matters and obtaining necessary innoculations (Olsson, Fahlen, \& Janson, 2008; Kasl \& Cobb, 1966).

Health-risk behaviour can be defined as any activity undertaken by people with a frequency or intensity that increases risk of disease or injury (Eaton, Kann, Kinchen et al., 2005; Nelson, Patience, \& MacDonald, 1999). The six priority health risk-behaviours according to the Centers for Disease Control and Prevention (CDC) are: alcohol and drug abuse, behaviours that contribute to unintentional injuries and violence including suicide, tobacco use, unhealthy dietary behaviours, physical inactivity, and sexual behaviours that contribute to unintended teen pregnancy and sexually transmitted infections, including HIV (Centers for Disease Control and Prevention, 2009). Health risky behaviours are mostly acquired during adolescence and their results are reflected on to adulthood, and also influence cognitive performance, emotions, and overall quality of life (Patience \& MacDonald, 1999; Anderson \& Mueller, 2008). Changing health risk-behaviour has been shown to decrease morbidity and mortality and enhance quality of life (Adriana \& Catrinel, 2007).

National Youth Risk Behaviour Survey conducted in USA in 2009 revealed a negative association between health risk behaviours and academic achievement among high school students after controlling for sex, race/ethnicity and grade level (Centers for Disease Control and Prevention, 2009). It was reported that in Philippines, four out of ten important causes of deaths among youth and young adults aged 10-24 years are attributable to health risk behaviours (Karl \& Supa, 2011).

Some studies done in Africa including Botswana and Nigeria reported that adult behavioural pattern such as drinking, smoking and premarital sexual activities started from secondary schools, and they constituted major health problems of secondary school students (Isaiah \& Ola, Boriffice, 2004; Martin, 2011)

Little is known about the health risk behaviours and the factors responsible in rural and urban secondary schools from this part of the country. We therefore designed our study to assess the health risky behaviours and the factors associated with it among secondary school students in urban and rural areas in Enugu, South-East Nigeria.

\section{Methods}

\subsection{Study Population}

Secondary school students in three rural and three urban schools in Enugu, South-East, Nigeria were the target population. Enugu is currently the capital of Enugu state, one of thirty-six states in Nigeria. The state has 17 Local Government Areas (LGAs), out of which nine are largely urban. There are 314 public and 308 private secondary schools in the state.

\subsection{Study Design, Sample Size and Sampling Techniques}

This cross-sectional school based study was conducted to assess health risk behaviours and factors associated with it among secondary school students in Enugu, South-East, Nigeria. A sample size of 360 was estimated, including $10 \%$ none response rate.

A total of 360 students were selected through multistage sampling technique. At the first stage, 3 LGAs each were selected randomly from the rural and urban areas. The second stage was random selection of one school per LGA. Schools selected were in Ugwuogo Nike, Agbani, Obeagu Awkunanaw, and Enugu metropolis. Third stage involved proportionate sampling of 60 students among the classes: Junior Secondary 1 (JSS1) to Senior Secondary 3 (SS3) in each school.

\subsection{Data Collection}

Questionnaires were pre-tested by $5 \%$ of the study participants. Structured self-administered questionnaires were distributed to all randomly selected students. The study was explained to the students, and they were informed that participation is voluntary, and were assured of confidentiality. Data were collected by research assistants. The first part of the questionnaire was socio-demographic characteristics of the participants, educational status and occupation of the parents, while the second part was involvement in various health risk behaviours such as: alcohol, tobacco, sexual activity, violence, and physical inactivity.

\subsection{Data Analysis}

Data were entered and analysed using Statistical Package for Social Science (SPSS) version 21. Frequency distribution was used for socio-demographic characteristics of the participants, occupation and education level of the parents, and involvement in health risk behaviours. Statistical significance of association between variables was assessed using Chi-square test at $\mathrm{p}<0.05$. 


\subsection{Ethical Clearance}

Ethical clearance was obtained from the Research Ethics Committee of UNTH. Also, permission was obtained from state commissioner for education and principals of the schools. Informed written consent was obtained from the participants.

\section{Results}

A total of 348 students returned questionnaires distributed to them. Majority of them were females $178(51.2 \%)$. Majority of them were Christians 340 (97.7\%), while 341 (97.9\%) were from Igbo ethnic group. All the participants were never married (Table 1).

Table 1. Socio-Demographic Characteristics of the Respondents

\begin{tabular}{llll}
\hline Variables & Category & Frequency & Percentage \\
\hline Sex & Male & 170 & 48.8 \\
Age (years) & Female & 178 & 51.2 \\
& $10-12$ & 65 & 18.7 \\
& $13-15$ & 144 & 41.4 \\
Religion & $16-18$ & 123 & 35.3 \\
& $19-21$ & 15 & 4.3 \\
& $>\quad 21$ & 1 & 0.3 \\
Ethnic group & Christianity & 340 & 97.7 \\
& Islam & 2 & 0.6 \\
Classes & Traditional & 6 & 1.7 \\
& Igbo & 341 & 97.9 \\
& Yoruba & 3 & 0.9 \\
Hausa & 1 & 0.3 \\
& Others & 3 & 0.9 \\
& JSS1 & 50 & 14.4 \\
& JSS2 & 40 & 11.5 \\
& JSS3 & 43 & 12.3 \\
& SS1 & 60 & 17.2 \\
& SS2 & 72 & 20.7 \\
& SS3 & 83 & 23.9 \\
& Married & 0 & 0 \\
& Never married & 348 & 348 \\
\hline
\end{tabular}

Table 2 reveals that many respondents $155(44.5 \%)$ had taken alcohol in the past. Only $18(31.6 \%)$ engaged in protected intercourse among those that had sex in the past. $58(16.7 \%)$ were not participating in sports and other physical exercises. 
Table 2. Health risk behaviours among participants

\begin{tabular}{lllllll}
\hline \multirow{2}{*}{ Health risk behaviour } & \multicolumn{2}{c}{ Yes } & & \multicolumn{2}{c}{ No } \\
\cline { 2 - 3 } \cline { 5 - 6 } & $\mathrm{N}$ & $\%$ & & $\mathrm{~N}$ & $\%$ \\
\hline Had taken alcohol in the past & 155 & 44.5 & & 193 & 55.5 \\
Had smoked tobacco before & 47 & 13.5 & & 301 & 86.5 \\
Had sex in the past & 57 & 16.4 & & 291 & 83.6 \\
Among those that had sex (57), Was the sex protected? & 18 & 31.6 & & 39 & 68.4 \\
Physical violence in the past & 208 & 59.8 & & 140 & 40.2 \\
Preferred food junks e.g biscuits, snacks etc & 131 & 37.6 & & 217 & 62.4 \\
Participated in sports and other physical exercises & 290 & 83.3 & & 58 & 16.7 \\
\hline
\end{tabular}

Table 3 shows more females 87/178 (48.9\%) than males 68/170 (40\%) consume alcohol. Majority of participants in age group 19-21 years 8/15 (53.3\%) consume alcohol. Most participants in JSS2 24/40 (60\%) consume alcohol.

Table 3. Drinking of alcohol and relationship with sex, age, and class of participants

\begin{tabular}{|c|c|c|c|c|c|c|c|c|c|}
\hline \multirow{2}{*}{ Variables } & \multirow{2}{*}{ Category } & \multicolumn{2}{|c|}{ Yes } & \multicolumn{2}{|c|}{ No } & \multirow{2}{*}{ Total } & \multirow{2}{*}{$\%$} & \multirow{2}{*}{$\mathrm{X}^{2}$} & \multirow{2}{*}{$\mathbf{P}$} \\
\hline & & $\mathrm{N}$ & $\%$ & $\mathrm{~N}$ & $\%$ & & & & \\
\hline \multirow{2}{*}{ Sex } & Male & 68 & 40.0 & 102 & 60.0 & 170 & 48.8 & \multirow{7}{*}{3.335} & \multirow[b]{2}{*}{0.078} \\
\hline & Female & 87 & 48.9 & 91 & 51.1 & 178 & 51.2 & & \\
\hline \multirow{5}{*}{ Age (Years) } & $10-12$ & 26 & 40.0 & 39 & 60.0 & 65 & 18.7 & & \multirow{5}{*}{0.912} \\
\hline & $13-15$ & 63 & 43.7 & 81 & 56.3 & 144 & 41.4 & & \\
\hline & $16-18$ & 58 & 47.2 & 65 & 52.8 & 123 & 35.3 & & \\
\hline & $19-21$ & 8 & 53.3 & 7 & 46.7 & 15 & 4.3 & & \\
\hline & $>21$ & 0 & 0 & 1 & 100 & 1 & 0.3 & & \\
\hline \multirow{6}{*}{ Class } & JSS1 & 17 & 34.0 & 33 & 66.0 & 50 & 14.4 & & \multirow{6}{*}{0.392} \\
\hline & JSS2 & 24 & 60.0 & 16 & 40.0 & 40 & 11.5 & & \\
\hline & JSS3 & 19 & 44.2 & 24 & 55.8 & 43 & 12.3 & \multirow{4}{*}{10.571} & \\
\hline & SS1 & 24 & 40.0 & 36 & 60.0 & 60 & 17.2 & & \\
\hline & SS2 & 29 & 40.3 & 43 & 59.7 & 72 & 20.7 & & \\
\hline & SS3 & 42 & 50.6 & 41 & 49.4 & 83 & 23.9 & & \\
\hline
\end{tabular}


Table 4 shows more females 33/178 (18.5\%) had sex in the past than males 24/170 (14.1\%). More participants in age group 19-21 5/15 (33.3\%) had sex in the past. Only 8/65 (12.3\%) of those in age group 10-12 years had sex in the past.

Table 4. Participants who had sex before and relationship with sex, age, and class

\begin{tabular}{|c|c|c|c|c|c|c|c|c|c|}
\hline \multirow{2}{*}{ Variables } & \multirow{2}{*}{ Category } & \multicolumn{4}{|c|}{ Had sex before Yes/No } & \multirow{2}{*}{ Total } & \multirow{2}{*}{$\%$} & \multirow{2}{*}{$\mathbf{X}^{2}$} & \multirow{2}{*}{$\mathbf{P}$} \\
\hline & & $\mathrm{N}$ & $\%$ & $\mathrm{~N}$ & $\%$ & & & & \\
\hline \multirow{2}{*}{ Sex } & Male & 24 & 14.1 & 146 & 85.9 & 170 & 48.8 & \multirow{3}{*}{2.371} & \multirow{3}{*}{0.306} \\
\hline & Female & 33 & 18.5 & 145 & 81.5 & 178 & 51.2 & & \\
\hline \multirow{5}{*}{ Age (Years) } & $10-12$ & 8 & 12.3 & 57 & 87.7 & 65 & 18.7 & & \\
\hline & $13-15$ & 25 & 17.4 & 119 & 82.6 & 144 & 41.4 & \multirow{6}{*}{7.122} & \multirow{4}{*}{0.524} \\
\hline & $16-18$ & 19 & 15.4 & 104 & 84.6 & 123 & 35.3 & & \\
\hline & $19-21$ & 5 & 33.3 & 10 & 66.7 & 15 & 4.3 & & \\
\hline & $>21$ & 0 & 0 & 1 & 100 & 1 & 0.3 & & \\
\hline \multirow{6}{*}{ Class } & JSS1 & 9 & 18.0 & 41 & 82.0 & 50 & 14.4 & & \\
\hline & JSS2 & 7 & 17.5 & 33 & 82.5 & 40 & 11.5 & & \\
\hline & JSS3 & 9 & 20.9 & 34 & 79.1 & 43 & 12.3 & \multirow{4}{*}{5.175} & \multirow{4}{*}{0.879} \\
\hline & $\mathrm{SS} 1$ & 10 & 16.7 & 50 & 83.3 & 60 & 17.2 & & \\
\hline & $\mathrm{SS} 2$ & 10 & 13.9 & 62 & 86.1 & 72 & 20.7 & & \\
\hline & $\mathrm{SS} 3$ & 12 & 14.5 & 71 & 85.5 & 83 & 23.9 & & \\
\hline
\end{tabular}

Table 5 shows that more males $28 / 170(16.5 \%)$ than females $19 / 178(10.7 \%)$ had smoked in the past. More participants in the age group 19-21 years $12 / 15$ (80\%) had smoked tobacco in the past, while $4 / 65(6.2 \%), 16 / 144$ $(11.1 \%), 15 / 123(12.2 \%)$ were in the age groups $10-12,13-15,16-18$ years respectively.

Table 5. Participants who had smoked tobacco before and relationship with sex, age, and class

\begin{tabular}{|c|c|c|c|c|c|c|c|c|c|}
\hline \multirow{2}{*}{ Variables } & \multirow{2}{*}{ Category } & \multicolumn{2}{|c|}{ Had smoked before } & \multicolumn{2}{|c|}{ Yes/No } & \multirow{2}{*}{ Total } & \multirow{2}{*}{$\%$} & \multirow{2}{*}{$\mathbf{X}^{2}$} & \multirow{2}{*}{$\mathbf{P}$} \\
\hline & & $\mathrm{N}$ & $\%$ & $\mathrm{~N}$ & $\%$ & & & & \\
\hline \multirow{2}{*}{ Sex } & Male & 28 & 16.5 & 142 & 83.5 & 170 & 48.8 & \multirow{3}{*}{6.246} & \multirow[b]{2}{*}{0.044} \\
\hline & Female & 19 & 10.7 & 159 & 89.3 & 178 & 51.2 & & \\
\hline \multirow{5}{*}{ Age (Years) } & $10-12$ & 4 & 6.2 & 61 & 93.8 & 65 & 18.7 & & \multirow{7}{*}{0.297} \\
\hline & $13-15$ & 16 & 11.1 & 128 & 88.9 & 144 & 41.4 & \multirow{6}{*}{9.563} & \\
\hline & $16-18$ & 15 & 12.2 & 108 & 87.8 & 123 & 35.3 & & \\
\hline & $19-21$ & 12 & 80.0 & 3 & 20.0 & 15 & 4.3 & & \\
\hline & $>21$ & 0 & 0 & 1 & 100 & 1 & 0.3 & & \\
\hline \multirow{6}{*}{ Class } & JSS1 & 4 & 8.0 & 46 & 92.0 & 50 & 14.4 & & \\
\hline & JSS2 & 6 & 12.0 & 44 & 88.0 & 50 & 11.5 & & \\
\hline & JSS3 & 7 & 16.3 & 36 & 83.7 & 43 & 12.3 & \multirow{4}{*}{8.544} & \multirow{4}{*}{0.576} \\
\hline & $\mathrm{SS} 1$ & 7 & 11.7 & 53 & 88.3 & 60 & 17.2 & & \\
\hline & $\mathrm{SS} 2$ & 8 & 11.1 & 64 & 88.9 & 72 & 20.7 & & \\
\hline & $\mathrm{SS} 3$ & 15 & 18.1 & 68 & 81.9 & 83 & 23.9 & & \\
\hline
\end{tabular}

Table 6 shows majority of males among the participants 124/170 (72.9\%) had engaged in physical violence in the 
past while females were 84/178. Physical violence was highest among the age group 19-21 years 11/15 (73.3\%), while age groups $10-12,13-15$, and 16-18 years were 28/65 (43.1\%), 81/144 (56.3\%), and 88/123 (71.5\%) respectively.

Table 6. Participants who had physical violence and relationship with sex, age, and class

\begin{tabular}{|c|c|c|c|c|c|c|c|c|c|}
\hline \multirow{2}{*}{ Variables } & \multirow{2}{*}{ Category } & \multirow{2}{*}{$\begin{array}{c}\text { Yes } \\
\mathrm{N}\end{array}$} & \multicolumn{3}{|c|}{ No } & \multirow{2}{*}{ Total } & \multirow{2}{*}{$\%$} & \multirow{2}{*}{$\mathbf{X}^{2}$} & \multirow{2}{*}{$\mathbf{P}$} \\
\hline & & & $\%$ & $\mathrm{~N}$ & $\%$ & & & & \\
\hline \multirow{2}{*}{ Sex } & Male & 124 & 72.9 & 46 & 27.1 & 170 & 48.8 & \multirow{3}{*}{0.00} & \multirow[b]{2}{*}{21.478} \\
\hline & Female & 84 & 47.2 & 94 & 52.8 & 178 & 51.2 & & \\
\hline \multirow{5}{*}{ Age (Years) } & $10-12$ & 28 & 43.1 & 37 & 56.9 & 65 & 18.7 & & \multirow{7}{*}{18.885} \\
\hline & $13-15$ & 81 & 56.3 & 63 & 43.7 & 144 & 41.4 & \multirow{6}{*}{0.015} & \\
\hline & $16-18$ & 88 & 71.5 & 35 & 28.5 & 123 & 35.3 & & \\
\hline & $19-21$ & 11 & 73.3 & 4 & 26.7 & 15 & 4.3 & & \\
\hline & $>21$ & 0 & 0 & 1 & 100 & 1 & 0.3 & & \\
\hline \multirow{6}{*}{ Class } & JSS1 & 16 & 32.0 & 34 & 68.0 & 50 & 14.4 & & \\
\hline & JSS2 & 23 & 57.5 & 17 & 42.5 & 40 & 11.5 & & \\
\hline & JSS3 & 23 & 53.5 & 20 & 46.5 & 43 & 12.3 & \multirow{4}{*}{0.000} & \multirow{4}{*}{33.149} \\
\hline & $\mathrm{SS} 1$ & 37 & 61.7 & 23 & 38.3 & 60 & 17.2 & & \\
\hline & $\mathrm{SS} 2$ & 51 & 70.8 & 21 & 29.2 & 72 & 20.7 & & \\
\hline & SS3 & 58 & 69.8 & 25 & 30.1 & 83 & 23.9 & & \\
\hline
\end{tabular}

Figure 7 reveals that $71 / 178$ (39.9\%) females preferred junk food while males were $60 / 170$ (35.3\%). Those who preferred junk food in age groups 10-12, 13-15, 16-18, and 19-21 years were 23/65 (35.4\%), 57/144 (39.6\%), $43 / 123(34.9 \%)$, and $7 / 15(46.7 \%)$ respectively.

Table 7. Participants who preferred food junks and relationship with sex, age, and class

\begin{tabular}{|c|c|c|c|c|c|c|c|c|c|}
\hline \multirow[t]{2}{*}{ Variables } & \multirow[t]{2}{*}{ Category } & \multicolumn{2}{|c|}{ Yes } & \multicolumn{2}{|c|}{ No } & \multirow[t]{2}{*}{ Total } & \multirow[t]{2}{*}{$\%$} & \multirow[t]{2}{*}{$\mathbf{X}^{2}$} & \multirow[t]{2}{*}{$\mathbf{P}$} \\
\hline & & $\mathrm{N}$ & $\%$ & $\mathrm{~N}$ & $\%$ & & & & \\
\hline \multirow[t]{2}{*}{ Sex } & Male & 60 & 35.3 & 110 & 64.7 & 170 & 48.8 & & \\
\hline & Female & 71 & 39.9 & 107 & 60.1 & 178 & 51.2 & 0.066 & 6.953 \\
\hline \multirow{5}{*}{ Age (Years) } & $10-12$ & 23 & 35.4 & 42 & 64.6 & 65 & 18.7 & & \\
\hline & $13-15$ & 57 & 39.6 & 87 & 60.4 & 144 & 41.4 & & \\
\hline & $16-18$ & 43 & 34.9 & 80 & 65.1 & 123 & 35.3 & 0.542 & 5.435 \\
\hline & $19-21$ & 7 & 46.7 & 8 & 53.3 & 15 & 4.3 & & \\
\hline & $>21$ & 1 & 100 & 0 & 0 & 1 & 0.3 & & \\
\hline \multirow[t]{6}{*}{ Class } & JSS1 & 22 & 44.0 & 28 & 56.0 & 50 & 14.4 & & \\
\hline & JSS2 & 15 & 37.5 & 25 & 62.5 & 40 & 11.5 & & \\
\hline & JSS3 & 18 & 41.9 & 25 & 58.1 & 43 & 12.3 & & \\
\hline & $\mathrm{SS} 1$ & 20 & 33.3 & 40 & 66.7 & 60 & 17.2 & 0.897 & 4.916 \\
\hline & $\mathrm{SS} 2$ & 26 & 36.1 & 46 & 63.9 & 72 & 20.7 & & \\
\hline & SS3 & 30 & 36.1 & 53 & 63.9 & 83 & 23.9 & & \\
\hline
\end{tabular}

Table 8 shows that higher prevalence of participants from the schools in urban areas $85(24.4 \%)$ had taken alcohol 
than those from the schools in rural schools 70 (20.1\%). More participants from schools in rural areas $33(9.5 \%)$ had used tobacco/ smoked cigarettes than those from urban schools 14 (4\%). More participants from rural areas 29 $(8.3 \%)$ had sex intercourse in the past than those in urban areas $28(8 \%)$.

Table 8. Participants health risk behaviours and relationship with schools in rural/urban

\begin{tabular}{|c|c|c|c|c|c|c|c|c|c|c|}
\hline \multirow{3}{*}{ Health risk behaviours } & \multicolumn{4}{|c|}{ Schools in Rural Areas } & \multicolumn{4}{|c|}{ Schools in Urban Areas } & \multirow{3}{*}{$\mathrm{X}^{2}$} & \multirow{3}{*}{$\mathbf{P}$} \\
\hline & \multicolumn{2}{|c|}{ Yes } & \multicolumn{2}{|c|}{ No } & \multicolumn{2}{|c|}{ Yes } & \multicolumn{2}{|c|}{ No } & & \\
\hline & $\mathbf{N}$ & $\%$ & $\mathbf{N}$ & $\%$ & $\mathbf{N}$ & $\%$ & $\mathbf{N}$ & $\%$ & & \\
\hline Had taken alcohol & 70 & 20.1 & 104 & 29.9 & 85 & 24.1 & 89 & 25.6 & 22.486 & 0.013 \\
\hline Tobacco use/ smoking & 33 & 9.5 & 141 & 40.5 & 14 & 4.0 & 160 & 46.0 & 29.695 & 0.001 \\
\hline Sex intercourse & 29 & 8.3 & 145 & 41.7 & 28 & 8.0 & 146 & 42.0 & 17.769 & 0.059 \\
\hline Physical violence & 120 & 34.5 & 54 & 15.5 & 88 & 25.3 & 86 & 24.7 & 47.737 & 0.000 \\
\hline Preferred food junks & 75 & 21.6 & 99 & 28.4 & 56 & 16.1 & 118 & 33.9 & 11.055 & 0.353 \\
\hline Sports and other exercises. & 152 & 43.7 & 22 & 6.3 & 138 & 39.7 & 36 & 10.3 & 29.205 & 0.001 \\
\hline
\end{tabular}

\section{Discussion}

A total of 360 students were included in our study with a response rate of $96.7 \%$. Majority of the respondents were between 13 and 18 years and with the mean age of $15.2 \pm 5.1$ years. This indicates that they were relatively young and in adolescent period when they are engaged in Health Risk Behaviours (HRB) such as alcohol consumption, tobacco use/cigarette smoking, sexual activities, physical violence, and unhealthy dietary behaviours. A little more than half of our participants were females. This is similar to studies conducted in some countries including Nigeria (Adeleye, Rohan, Paula, \& Shamin, 2009; John, Opirite, \& Eme, 2012). It is not surprising that majority of the participants were Christians because Christianity is the main religion in Southern Nigeria.

More than three quarters of participants in our study were older than 12 years, and majority were in senior classes (SS1-SS3). Majority of the parents of the participants had secondary education and above, but majority of them were civil servants and traders. This findings could be because the study was conducted in urban and rural areas of the country. Our study also showed that more than three quarters of the participants were living with both parents. This finding confirms that parents have a great role to play in health behaviours of students and not only schools.

Our study revealed that almost half of the participants had consumed alcohol in the past. This report is lower than the study conducted among undergraduate students in Nigeria where sixty-one percent was reported (John, Opirite, \& Eme, 2012). However, it is similar to the one done among high school students in USA (Miller, Naimi, Brewer, \& Jones, 2007). The result in our study could be as a result of easy accessibility to alcohol in the communities especially during ceremonies such as wedding, burial and child dedication. Many studies showed high alcohol consumption among adults in the study areas. Surprisingly, more females had consumed alcohol in this study. This could be because more females attend ceremonies than males. The study also showed that alcohol drinking rates increased with age and almost all participants in all school grades had drank alcohol except in JSS1 where only 34\% of the participants were involved. This health risk behaviour should be discouraged as studies have demonstrated that students who drank alcohol were more likely to have poor academic performance, negative effects on some organs, and engage in other health risk behaviours such as irresponsible sexual activities, violence, smoking cigarettes and other drugs abuse (Miller, Naimi, Brewer, \& Jones 2007, McCarty, Ebel, Garriso et al., 2004). Also, studies conducted in Western countries and sub-Saharan Africa have reported consistent causal relationships between alcohol consumption and sexual risk behaviours, sexual violence and HIV/AIDS (George \& Stoner, 2000; Leigh, 2002; Qing, Xiaoming, \& Bonita, 2010; Weinhardt \& Carey, 2000; World Health Organization, 2005).

The prevalence of $13.5 \%$ in our study concerning smoking of cigarettes is lower than the percentage of US high school students who engaged in smoking where prevalence of $16-52 \%$ was reported in the United State Youth Risk Behaviour Survey in 2009 (Centers for Disease Control and Prevention, 2009). It is also lower than the findings in the studies done in Philippines and the English-speaking Caribbean (Karl et al., 2016; Rohan et al., 2009). However, the findings are similar to some studies in Nigeria (Ekanem, Asuzu Anunobi et al., 2010; Adeleye, 2011). Our findings is slightly higher than the result of the tobacco survey conducted in 2007 among youth in Nigeria (Aghaji, Omotowo, \& Ekwueme, 2010), and in the study conducted in Northern Nigeria among in school 
adolescents where prevalence of $7.6 \%$ and $8.3 \%$ were reported respectively (Raji, Abubakar, Oche, \& Kaoje, 2013). The difference could be because all participants in our study were day students unlike the study done in Northern Nigeria where about $72 \%$ of them were day students. More males abuse tobacco just like in some other studies conducted in Nigeria and other countries (Karl et al., 2016; Rohan et al., 2009; Ekanem et al., 2010; Adeleye, 2011; Aghaji et al., 2010; Raji et al., 2013). Our findings revealed also that rate of smoking increases with age and class of students. This finding was not statistically significant.

Our study revealed that $16.4 \%$ of the participants had sex in the past. This result is slightly lower than the findings in studies done in Nigeria (Adeleye et al., 2014) and Ethiopia (Emebet, S. Debebe, \& T. Deresse, 2014) where they reported prevalence of $22.9 \%$ and $18.3 \%$ respectively. The prevalence of the participants that had sexual intercourse with condom (31.6\%) among those that had sex in our study was lower than $51.4 \%$ reported in the study conducted in Ethiopia. The differences could be due to the fact that those studies were conducted among only female students unlike in our study that involved both males and females. This findings concerning high prevalence of participants that had intercourse without condom could be due to lack of effective sexuality education among adolescents in schools (World Health Organization, 2012). This is a very dangerous trend that could lead to increase in teenage pregnancies, abortion, sexual transmitted diseases including HIV/AIDS.

When we examined the relationship between the participants that had sex in the past with sex, age and class, the proportion of females that had sex was higher $18.5 \%$ compared to $14.1 \%$ among males. Our study revealed that the prevalence of participants that had sex also increases with age and class of the participants. This is similar to findings in some other studies conducted in Nigeria and Ethiopia (Adeleye et al., 2014; John et al., 2012; Emebet et al., 2014).

In our study, more than half (59.8\%) had engaged in physical violence, but more males had significantly engaged in physical violence than females. This is not surprising because males take more physical risks than females. Also the prevalence of participants that engaged in physical violence significantly increases with the age and class.

The findings of our study concerning dietary behaviour showed that $37.6 \%$ preferred junk food, but more among females $39.9 \%$ compared to males $35.3 \%$. This findings differ from the study conducted among undergraduates in Egypt (Abolfotouh, Bassiouni, Mounir, \& Fayyad, 2007). This mean that students in higher institutions engaged more in unhealthy dietary behaviours. The prevalence of unhealthy dietary behaviours in this study also increases with age and class of the participants.

Our study revealed that almost all participants $83.3 \%$ reported engagement in physical activity. The findings showed that more males participated in physical activities than females. This could be because males are more mobile and exercise with their peers more often than females.

Our study revealed significant disparity in health risk behaviours among participants in secondary schools in rural and urban areas. Participants from schools in rural areas engaged more in health risk behaviours than those that were in urban areas. More students in rural areas had taken alcohol before, had used tobacco, had sex, involved in physical violence, and unhealthy dietary behaviour. However, the prevalence of participants that drank alcohol and engaged in physical inactivity were more among students in urban areas than rural areas. The findings are different from the study done in Canada where they reported no difference in involvement of health risk behaviours among urban, semi urban and rural areas (Pirie \& Simmons 2014).

\section{Conclusions \& Recommendations}

The prevalence of health risk behaviours was high among students in secondary schools both in rural and urban areas in our study. We therefore recommended awareness creation among parents, community members, school staff, and the students by media to bring about behavioural changes in terms of alcohol consumption, smoking, sexual activities, healthy dietary habits, physical violence and physical activity practiced by the students. A peer-education programme should be introduced where students in schools encourage each other on adopting good health behaviour and discourage risky ones.

\section{Acknowledgments}

We sincerely thank Enugu State Commissioner of Education. We acknowledged the principals, and students of the schools where this study was conducted. The authors also thank the research assistants; Akubuko, Akwazie, Alor and Alum that collected the data for their commitment.

\section{Competing Interests Statement}

The authors declare that there is no conflict of interests regarding the publication of this paper. 


\section{References}

Abolfotouh, M. A., Bassiouni, F. A., Mounir.G. M., \& Fayyad, R. Ch. (2007). Health-related lifestyles and risk behaviours among students living in Alexandria University hostels. Eastern Mediterranean Health Journal; 13(2), 376-390.

Adeleye, A. A., Oluwatosin, A. A., Adefisoye, A., Oluwaseyi, I., \& Abiola, T., U. (2014). Sexual Risk Behaviours among Adolescents attending Secondary Schools in a Southwestern State in Nigeria. Journal of Behavioral Health, 3(3), 176-181. https://doi.org/10.5455/jbh.20140815092416

Adeleye, O. O. (2011). Cigarette smoking habits among senior secondary school students in Lagos, South West, Nigeria. Int J Biol Med Res, 2(4), 1047-1050.

Adriana, B., \& Catrinel, C. (2007). Changing health-risk behaviours: A review of theory and evidence-based interventions in health psychology. Journal of evidence-based psychotherapies, 7(1), 45-67

Aghaji, M., N., Omotowo, I., B., \& Ekwueme, O. C. (2010). Technical Report on the 2007 Nigerian Youth Tobacco Survey (pp. 158-201). Research for International Tobacco Control of the International Development Research Center, Ottawa, Canada.

Anderson, J., E., \& Mueller, T. E. (2008). Trends in sexual risk behaviour and unprotected sex among high school students. Journal of School Health, 78(11), 575-580. https://doi.org/10.1111/j.1746-1561.2008.00348.x

Boriffice, O. B. (2004). Recreation and health behaviour of adolescents. Ibadan: Royal People, 112-14.

Centers for Disease Control and Prevention. (2009). The National Youth Risk Behaviour Survey (YRBS) in USA.

Collins, W., A., \& Steinberg, L. (2006). Adolescent development in interpersonal context. Handbook of Child Psychology (pp. 1003-1067). Hoboken, NJ: John Wiley and sons.

Eaton, D., K., Kann, I., Kinchen, S., Ross, J., Hawkins, J., \& Harris, W. A. et al. (2005). Youth risk behaviour surveillance, Unitedn States. Morbidity and Mortality Weekly Report, 55(5), 1-9.

Ekanem, I., A., Asuzu, M., C., Anunobi, C.C et al. (2010). Prevalence of tobacco use among youths in five centres in Nigeria: A global youth tobacco survey (GYTS) approach. Journal of Community Medicine \& Primary Health Care, 22(1-2), 62-64.

Emebet, T., Debebe, S., \& Deresse, D. (2014). Prevalence, associated risk factors and consequences of premarital sex among female students in Aletawondo High School, Sidama Zone, Ethiopia. Journal of Public Health and Epidemiology, 6(7), 216-222. https://doi.org/10.5897/JPHE2014.0640

George, W., H., \& Stoner, S. A. (2000). Understanding acute alcohol effects on sexual behaviour. Annu Rev Sex Res. 11, 92-110.

Isaiah, O., O., \& Ola, T. A. (2016). Predictors of Risky Health Behaviours Among Secondary School Students with Hearing Impairment in South-West, Nigeria. European Scientific Journal, 12(10), 211-223. https://doi.org/10.19044/esj.2016.v12n10p211

John, F., Mattew, K., Rashed, A., \& Will. (2012). Health and health-related behaviours among young people: Ontario. Ministry of Education, Government of Ontario.

John, A. I., Opirite, B., P. K., \& Eme, O. A. (2012). Pattern of risky sexual behaviour and associated factors among undergraduate students of the University of Port Harcourt, Rivers State, Nigeria. Pan Afr Med J, 12, 97.

Kasl, S., A., \& Cobb, S. (1966). Health behaviour, illness behaviour, and sick role behaviour: Health and illness behaviour. Archives of Environmental Health, 12, 24M6.

Karl, P., \& Supa, P. (2016). Health Risk Behaviour among In-School Adolescents in the Philippines: Trends between 2003, 2007 and 2011. A Cross-Sectional Study. International Journal of Environmental Research and Public Health, 13, 73.

Kolek, E. A. (2006). Recreational prescription drug use among college students. NASPA Journal, 43, 19-39. https://doi.org/10.2202/0027-6014.1569

Leigh, B. C. (2002). Alcohol and condom use: a meta-analysis of event-level studies. Sex Transm Dis., 29(8), 476-79. https://doi.org/10.1097/00007435-200208000-00008

Martin, M. M. (2011). Health risk behaviours among secondary school students in Botswana: Physical activity and health. African Journal for Physical Health Education, Recreation and Dance, 17, 481-88.

McCarty, C. A., Ebel, B. E., Garrison, M. M., DiGiuseppe, D. L., Christakis, D. A., \& Rivara, F. P. (2004). 
Continuity of binge and harmful drinking from late adolescence to early childhood. Paediatrics, 114, 714-719. https://doi.org/10.1542/peds.2003-0864-L

Miller, J. W., Naimi, T. S., Brewer, R. D., \& Jones, S. E. (2007). Binge Drinking and Associated Health Risk Behaviours Among High School Students. Paediatrics, 119(1), 76-85. https://doi.org/10.1542/peds2006-1517

Nelson, B. V., Patience, T. H., \& MacDonald, D. C. (1999). Adolescent Risk Behaviours and the influence of Parents and Education. Journal of the American Board of Family Practice, 12(6), 436-443. https://doi.org/10.3122/jabfm.12.6.436

Olsson, A., Fahlen, I., \& Janson, S. (2008). Health behaviours, risk taking, and conceptual changes among school children aged 7 to 19 years in semi-rural Sweden. Child Health Care Dev, 34(3), 302-9. https://doi.org/10.1111/j.1365-2214.2008.00836.x

Pirie, T., \& Simmons, M. (2014). Cannabis Use and Risky Behaviours and Harms: A Comparison of Urban and Rural Populations in Canada. Canada Centre on Substance Abuse, 1-13

Qing, Li., Xiaoming, Li., \& Bonita, S. (2010). Alcohol Use and Sexual Behaviours and Outcomes in China: A Literature Review. AIDS Behav, 14(6), 1227-1236. https://doi.org/10.1007/s10461-009-9648-514

Raji, M., O., Abubakar, I., S., Oche, M., O., \& Kaoje, A., U. (2013). Prevalence and Determinants of Cigarette Smoking among in School Adolescents in Sokoto Metropolis, North West Nigeria. International Journal of Tropical Medicine, 8(3), 81-86.

Rohan, G., M., Paula, N., \& Shamin, R. (2009). Health risk behaviours among adolescents in the English-speaking Caribbean: a review. Child Adolesc Psychiatry Ment Health, 3(1), 10. https://doi.org/10.1186/1753-2000-3-10

Schwartz, S. J., Forthun, L., Ravert, R. D., et al. (2010). Identity consolidation and health risk behaviours in college students. American Journal of Health Behaviour, 34(2), 214-224. https://doi.org/10.5993/AJHB.34.2.9

Weinhardt, L. S., \& Carey, M. P. (2000). Does alcohol lead to sexual risk behaviour? Findings from event-level research. Аппи Rev FRes, 11, 125-130.

World Health Organization. (2005). Alcohol use and sexual risk behaviour: A cross-cultural study in eight countries.

World Health Organization. (2012). Early marriages, adolescent and young pregnancies.

\section{Copyrights}

Copyright for this article is retained by the author(s), with first publication rights granted to the journal.

This is an open-access article distributed under the terms and conditions of the Creative Commons Attribution license (http://creativecommons.org/licenses/by/4.0/). 